\title{
El poder de decisión del juez en un Estado de derecho: aportes de Max Weber al debate actual
}

\section{The Power of Decision of the Judge in a Rule of Law: Contributions of Max Weber to the Current Debate}

Frank Harbottle Quirós*

http://dx.doi.org/10.21503/lex.v16i22.1646

\footnotetext{
* Doctorando en Derecho y máster en Criminología de la Universidad Estatal a Distancia. Licenciado en Derecho con honores de la Universidad de Costa Rica. Especialista en Derechos Fundamentales y Garantías Constitucionales en el Derecho Penal y Procesal Penal, Universidad de Castilla - La Mancha, España. Diploma en Ciencias Criminales y Dogmática Penal Alemana, Georg-August Universität Göttingen, Alemania. Posgrado en Control de Constitucionalidad y Convencionalidad de los Derechos, Universidad de Buenos Aires, Argentina. Profesor de la Facultad de Derecho de la Universidad de Costa Rica y docente del Colegio de Abogados y Abogadas de Costa Rica. Ha publicado más de veinticinco obras (libros, artículos en revistas científicas especializadas) en Costa Rica, España, Uruguay, Paraguay, Chile y Nicaragua.

Correo electrónico: frankharbottle@gmail.com
}

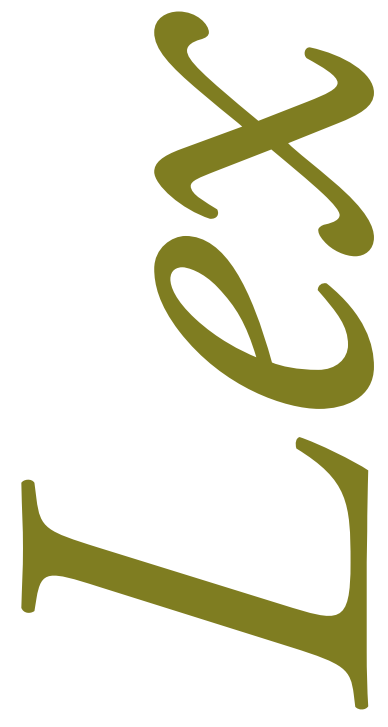




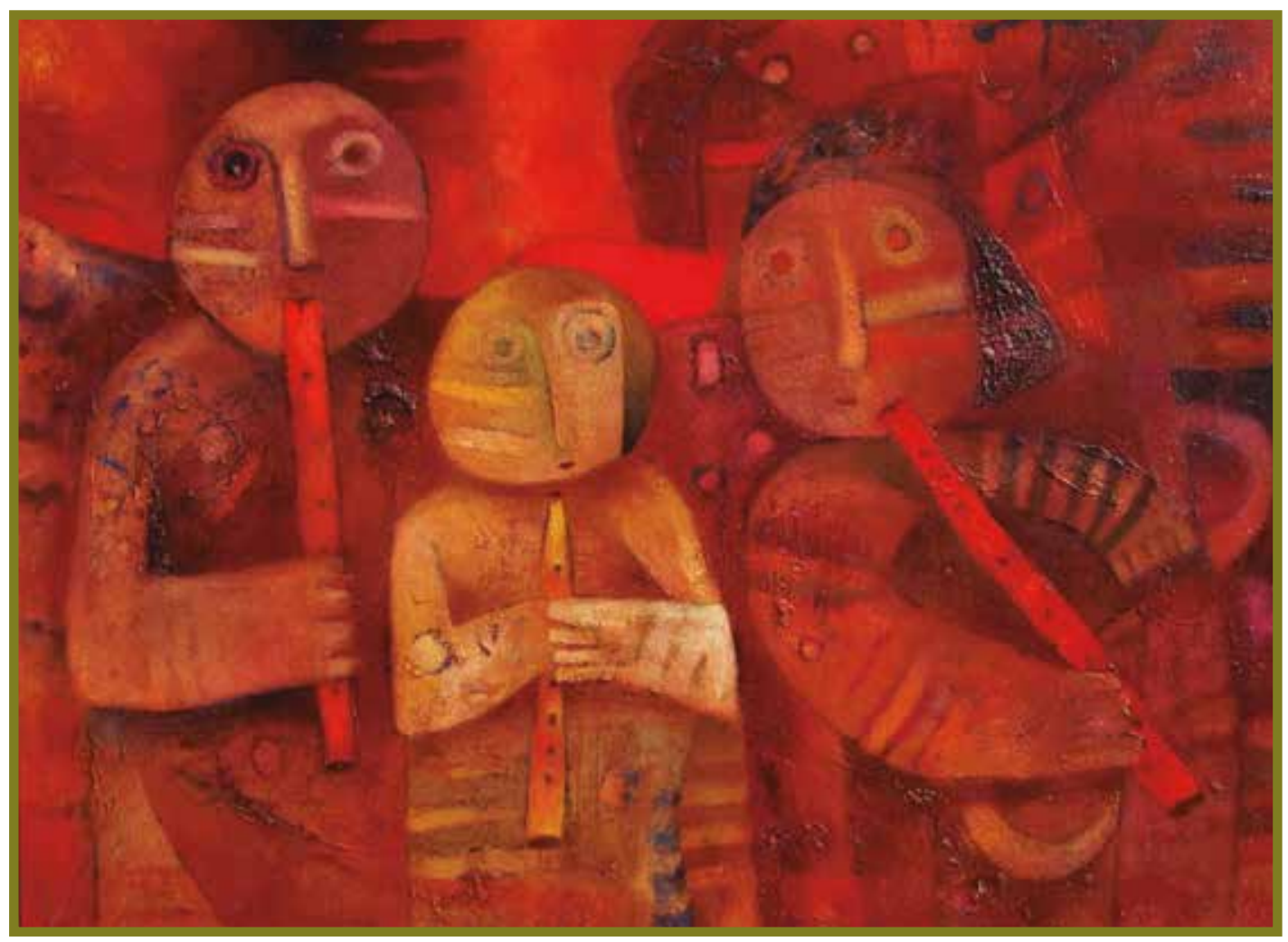

Niños flautistas. Pintura. Juan Carlos Nananake. 


\section{RESUMEN}

En la investigación se reflexiona sobre la labor de los jueces en un Estado de derecho, tomando como punto de partida el principio de división de poderes. Se expone la posición asumida por Max Weber en la obra Economía y Sociedad, en relación con la creación y aplicación del derecho. Se establece, en este artículo, que la temática en cuanto a si los jueces crean derecho o no se encuentra vigente, al no estar acabado el debate entre reglas y principios. Se concluye, en relación con la interpretación del derecho, que la fundamentación de las sentencias es una garantía político-institucional debido a que permite controlar la actividad jurisdiccional y, consecuentemente, la legitimidad democrática de los jueces.

Palabras clave: decisión judicial, Estado de derecho, fundamentación de sentencias, legitimidad.

\section{ABSTRACT}

In the investigation reflects on the work of judges in a Rule of Law, taking as a starting point the principle of division of powers. The position assumed by Max Weber in the work "Economy and Society" is exposed, in relation to the creation and application of Law. It is established, in this article, that the topic as to whether the judges create or not Law keepscurrent, because the debate between rules and principles is not over. It is concluded, in relation to the interpretation of Law, that the foundation of the judgments in a political-institutional guarantee because it allows to control the jurisdictional activity and, consequently, the democratic legitimacy of the judges.

Key words: judicial decision, rule of law, foundation of judgments, legitimacy. 


\section{INTRODUCCIÓN}

En la actualidad, a nivel mundial, existe un importante debate sobre el rol que desempeñan los jueces en un Estado de derecho. Se mantiene la inquietud de hasta qué punto los jugadores crean derecho o no. Está discusión no está acabada, de modo tal que, en estas líneas, se pretende reflexionar al respecto.

En este trabajo, en un primer apartado, se conceptualiza al Estado de derecho, partiendo de la división de poderes.

Luego, se procede con el estudio de la labor de los jueces en la aplicación del derecho desde la perspectiva de Max Weber (tomando como base su obra Economía y sociedad), y su trascendencia hoy en día a lo largo y ancho del planeta.

Posteriormente, se analiza la legitimidad del juez en un Estado de derecho y la importancia que reviste la fundamentación de las sentencias como mecanismo para controlar la actividad jurisdiccional en este modelo de Estado.

Finalmente, se presentan las conclusiones de esta investigación.

\section{EL ESTADO DE DERECHO Y LA DIVISIÓN DE PODERES}

El Estado constituye una forma política de asociación humana mediante la cual una sociedad se organiza bajo la acción de un Gobierno que reclama la soberanía legítima sobre un área territorial, autoridad sobre todos los miembros de la sociedad y el derecho de usar la fuerza física cuando sea necesario para asegurar el efectivo ejercicio de su control legítimo. ${ }^{1}$

El Estado de derecho, dentro del cual se enmarca este artículo, presenta, entre otros rasgos característicos, la supremacía o imperio de la ley y el reconocimiento de las libertades fundamentales del ciudadano, lo cual no ocurre en un Estado absolutista.

1 George Theodorson y Achilles Theodorson, Diccionario de sociología (Buenos Aires: Editorial Paidós, 1978), 108. 
El Estado de derecho es uno de esos conceptos amplios y genéricos que tienen múltiples y variadas ascendencias en la historia del pensamiento político: la idea, que se remonta a Platón y a Aristóteles, del "gobierno de las leyes" contrapuesto al "gobierno de los hombres", la doctrina medieval del fundamento jurídico de la soberanía, el pensamiento político liberal sobre los límites de la actividad del Estado y sobre el Estado mínimo, la doctrina iusnaturalista del respeto de las libertades fundamentales por parte del derecho positivo, el constitucionalismo inglés y norteamericano, la tesis de la separación de poderes, la teoría jurídica del estado elaborada por la ciencia alemana del derecho público del siglo pasado y después por el normativismo kelseniano. ${ }^{2}$

Históricamente, en Europa el Estado de derecho nace de la Revolución Francesa, cuyo objetivo había sido garantizar la libertad y la igualdad de los ciudadanos y acabar con los privilegios del clero y de la nobleza. Se desarrolla como Estado legislativo de derecho, y significa la sumisión de la Administración y del juez a la ley, que, por cuanto norma general y abstracta y expresión de la voluntad general, es también garantía de justicia, por lo que la Administración solo puede actuar previa habilitación legislativa. ${ }^{3}$

Estado liberal y Estado de derecho triunfan en el siglo XIX, siendo las últimas décadas de ese siglo las que marcan su apogeo en la mayoría de los países civilizados. ${ }^{4}$

En el siglo XX, surge el Estado social de derecho, definido como aquel que acepta e incorpora al ordenamiento jurídico, a partir de su propia Constitución, derechos sociales fundamentales junto a los clásicos políticos y civiles, fomentando una intervención en beneficio de la igualdad más que en la propiedad o la libertad.

En la actualidad, el Estado de derecho constituye un orden constitucional en el que todos los órganos estatales están sometidos a las leyes votadas por organismos democráticos y al control de los jueces; se trata de un Estado que concede la primacía al derecho y en el que el poder está limitado por este último. ${ }^{5}$

Hoy, incluso, la mayor parte de los Estados utilizan la terminología Estado constitucional de derecho.

Al respecto, Ferrajoli' ${ }^{6}$ apunta que el Estado de derecho designa no solamente un "Estado legal", sino un modelo de Estado nacido con las modernas constituciones y caracterizado:

\footnotetext{
Luigi Ferrajoli, Derecho y razón. Teoría del garantismo penal (Madrid: Editorial Trotta, 2011), 855-856.

3 Marina Gascón Abellán y Alfonso García Figueroa, La Argumentación en el derecho. Algunas cuestiones fundamentales (Lima: Palestra Editores, 2003), 15-20.

4 Ángel Latorre, Introducción al derecho (Barcelona: Ariel, 2012), 48.

5 Karl Hillmann, Diccionario enciclopédico de sociología (Barcelona: Editorial Herder, 2001), 302.

6 Ferrajoli, Derecho y razón. Teoría del garantismo penal, 856-857.
} 
a) en el plano formal, por el principio de legalidad, en virtud del cual todo poder público legislativo, judicial y administrativo- está subordinado a leyes generales y abstractas (legitimación formal), que disciplinan sus formas de ejercicio y cuya observancia se halla sometida a control de legitimidad por parte de jueces separados del mismo e independientes (el Tribunal Constitucional para las leyes, los jueces ordinarios para las sentencias, los tribunales administrativos para las decisiones de ese carácter); b) en el plano sustancial, por la funcionalización de todos los poderes del Estado al servicio de la garantía de los derechos fundamentales de los ciudadanos (legitimación sustancial).

Tal y como lo señala Ezquiaga Ganuzas, ${ }^{7}$ uno de los principios estructurales más importantes que caracterizan al Estado democrático y de derecho es el de la separación de poderes. No obstante, contrario al modo en el que en ocasiones es presentado, este, más que una rígida separación entre los poderes Legislativo, Ejecutivo y Judicial, implica una distribución de funciones ordenada entre ellos, de modo tal que al Poder Legislativo le compete la creación del derecho (la función legislativa), mientras que a los órganos pertenecientes al Poder Judicial les corresponde la aplicación del derecho creado por los órganos legislativos (la función judicial o jurisdiccional), estableciéndose de esta forma, una subordinación (si bien no orgánica, al menos sí) funcional del juez al legislador que suele expresarse como "la sujeción del juez a la ley".

La división de poderes, planteada por Montesquieu, fue abordada por el sociólogo alemán Max Weber, quien al referirse a la administración pública, en el sentido más amplio, indicó que esta "...encierra tres clases de tareas, a saber: creación del derecho, aplicación del mismo y lo que queda de la actividad de los institutos públicos después de separar aquellas dos esferas: lo que llamaremos 'gobierno'...".

Las próximas líneas se centrarán en la aplicación del derecho, desde la óptica de Weber, para, posteriormente, proceder al estudio de un tema polémico que mantiene plena vigencia, a saber, si el juez debe desempeñar siempre una labor autómata, en palabras de Montesquieu, ser "bouche de la loi" ("boca de la ley") o si, por el contrario, en determinadas circunstancias, su actividad puede ser "creadora" o ir más allá de las normas.

7 Francisco Ezquiaga Ganuzas, “Función legislativa y función judicial: la sujeción del juez a la ley”, en La función judicial. Ética y democracia, ed. por Jorge Malem, Jesús Orozco y Rodolfo Vásquez (Barcelona: Editorial Gedisa S. A., 2003), 3940.

8 Max Weber, Economía y sociedad. Edición revisada, comentada y anotada por Francisco Gil Villegas (México: Fondo de Cultura Económica, 2014), 728. 


\section{LOS JUECES Y LA APLICACIÓN DEL DERECHO: PERSPECTIVA DE MAX WEBER}

Entre los mayores aportes de Max Weber en el campo de la sociología y — de una u otra forma- en el derecho, debe mencionarse, sin duda alguna, el desarrollo histórico que presenta en su obra Economía y sociedad, publicada en 1922, en la que expone que la actividad judicial de tipo irracional constituye la forma primitiva de la aplicación del derecho y ha dominado total o parcialmente en el pasado, a excepción del ámbito de aplicación del derecho romano, aclarando que, posteriormente, de manera progresiva el derecho se fue conduciendo hacia una mayor racionalidad y sistematicidad, pero con el trascurso de los ańos se ha dado nuevamente un auge de lo material e irracional.

Weber ${ }^{9}$ entiende por creación del derecho, el establecimiento de normas generales integradas, según el lenguaje de los juristas,por uno o varios "preceptos jurídicos", en tanto la aplicación del derecho la concibe como la subsunción de normas generales y preceptos singulares que el pensamiento jurídico deriva de ellas a "hechos concretos", de modo tal que, desde su perspectiva, la distinción entre creación de "normas jurídicas" y "aplicación" de las mismas a casos concretos no existe cuando la actividad judicial, como simple "administración", aparece formando un conjunto de decisiones libres que pueden variar en cada caso.

Desde la óptica de este autor, la aplicación del derecho (al igual que su creación) puede ser racional o irracional.

Es irracional desde el punto de vista formal, cuando para la regulación de la actividad judicial se recurre a procedimientos no controlados racionalmente, y desde el punto de vista material, cuando la decisión de los diversos casos depende esencialmente de apreciaciones valorativas concretas de índole ética, sentimental o política y no de normas generales.

Es racional en sentido formal cuando lo jurídico material y lo jurídico procesal no tienen en cuenta más que características generales, "unívocas", de los hechos. Se está en presencia de una racionalización material cuando en la decisión de los problemas jurídicos influyen ciertas normas cuya dignidad cualitativa es diversa de la que corresponde a las generalizaciones lógicas que se basan en una interpretación abstracta: imperativos éticos, reglas utilitarias y de conveniencia, o postulados políticos que rompen tanto con el formalismo de las características externas como con el de la abstracción lógica.

Weber es claro en su posición en el sentido de que “... únicamente la abstracción interpretativa hace posible la tarea sistemática que consiste en ordenar y racionalizar con ayuda de la

9 Weber, Economia y sociedad, 737. 
lógica, las reglas jurídicas cuya validez se acepta, formando con ellas un sistema coherente de preceptos abstractos...". ${ }^{10}$

Según lo expone este autor, con la aparición de los modernos problemas de clase surgieron diversas exigencias materiales dirigidas al derecho de parte de un sector de los particulares (principalmente la clase trabajadora), así como de los ideólogos juristas, dejando en entredicho el formalismo del derecho, al descansar sobre normas antiformales, sin carácter jurídico, convencional o tradicional, sino puramente ético (postulados morales como "justicia" y "dignidad humana"), las cuales, más que una legalidad formal, representaban una justicia material.

De acuerdo con este destacado sociólogo alemán, con el pasar de los años, en la actividad judicial se vino imponiendo al juez, por medio de normas jurídicas, así como doctrinalmente “... la obligación de resolver las controversias de que conoce, atendiendo a principios materiales: moralidad, equidad, conveniencia, etc....". ${ }^{11}$

De esta forma, pone en la palestra la situación de los autómatas jurídicos ligados a la simple interpretación de contratos y artículos de la ley, comparables a aparatos en los que se introduce por la parte de arriba el hecho jurídico para que arrojen por abajo la sentencia, y por otro lado, a los juristas prácticos modernos que exigen del juez una actividad "creadora", al menos en aquellos casos en que las leyes enmudecen ante la existencia inevitable de lagunas, para quienes la plenitud hermética del derecho es una ficción.

Tal y como este autor lo expuso, la doctrina del derecho libre (contraparte alemana del realismo norteamericano) intentó demostrar que las omisiones representan el destino inevitable de todas las leyes, frente a la irracionalidad de los hechos, por lo cual, en ocasiones numerosas, solo en apariencia hay simple interpretación y la decisión es y tiene que ser emitida no de acuerdo con normas formales, sino con juicios concretos de valor. ${ }^{12}$

Detrás de lo planteado por Weber, está el debate en cuanto a si los jueces crean o no derecho, tema que mantiene plena vigencia hoy en día, siendo que ha recibido respuestas muy disímiles. Han surgido diversas teorías que buscan dar una explicación, posturas sobre las que se hará una breve mención en el siguiente apartado.

Weber, Economía y sociedad, 740.

Weber, Economia y sociedad, 740.

2 Weber, Economía y sociedad, 924-925. 


\section{LOS JUECES Y LA APLICACIÓN DEL DERECHO: ACTUALIDAD DEL DEBATE}

De acuerdo con la doctrina tradicional, entre la creación del derecho por parte del legislador y su aplicación por los tribunales de justicia, existe una tajante distinción, la cual tiene sus raíces en la Ilustración, la Revolución Francesa y la codificación napoleónica, que es una consecuencia casi necesaria de la doctrina de división de poderes. ${ }^{13}$

La ideología dominante en la filosofía del derecho y la política europea del siglo XIX fue la doctrina de la división de poderes, según la cual, tarea del legislador era formular normas claras e inequívocas, y la del juez aplicar estas normas a los casos concretos. Bajo esta perspectiva, a los jueces les corresponde subsumir los hechos del caso que se les presenta bajo la norma jurídica general. ${ }^{14}$

Esta tesis ha sido denominada por Aguiló ${ }^{15}$ como "deductivismo extremo", que consiste en considerar que el derecho objetivo es completo y cerrado, de forma que suministra todos los criterios necesarios para resolver todos los casos posibles, por lo que la argumentación resulta inútil; es algo tan vano como pretender argumentar en favor de una operación aritmética.

Desde esta postura, la labor del juez se limita a una actividad mecánica, a la mera aplicación de las normas al caso concreto, al estimarse que el derecho es un sistema completo y cerrado en el que pueden deducirse soluciones para todos los casos posibles.

Esta tesitura no solo supone una división tajante entre la creación y la aplicación del derecho, sino que además exige - para que los jueces estén en condiciones de cumplir su función - que el derecho les suministre la posibilidad de resolver todos los casos mediante la aplicación de las normas generales. Esto implica que el derecho ha de ser completo y coherente, en el sentido de que debe contener una solución para todo problema que sea sometido al juez y que no haya dos o más soluciones incompatibles para el mismo caso. ${ }^{16}$

Según lo explica Weber, para su época, la investigación jurídica tenía como punto de partida —al menos en aquella de sus ramas que alcanzó el grado más alto de racionalidad metódica- los siguientes postulados:

13 Eugenio Bulygin, “Los jueces ¡crean derecho?”, en La Función Judicial. Ética y Democracia, ed. por Jorge Malem, Jesús Orozco y Rodolfo Vásquez (Barcelona: Editorial Gedisa S.A., 2003), 22.

14 Eveline Feteris, Fundamentos de la argumentación jurídica. Revisión de las teorías sobre la justificación de las decisiones judiciales (Bogotá: Universidad Externado de Colombia, 2007), 27.

15 Josep Aguiló Regla, Teoría general de las fuentes del derecho (y el orden jurídico) (Barcelona: Editorial Ariel, 2012), 129132.

16 Bulygin, Los jueces ¿crean derecho?, 22. 
1) toda decisión jurídica concreta representa la "aplicación" de un precepto abstracto a un "hecho" concreto; 2) que sea posible encontrar, en relación con cada caso concreto, gracias al empleo de la lógica jurídica, una solución que se apoye en los preceptos abstractos en vigor; 3) el derecho objetivo vigente es un sistema "sin lagunas" de preceptos jurídicos o encierra tal sistema en estado latente o, por lo menos, tiene que ser tratado como tal para los fines de la aplicación del mismo a casos singulares; 4) todo aquello que no es posible "construir" de un modo racional carece de relevancia para el derecho; 5) la conducta de los hombres que forman una comunidad tiene que ser necesariamente concebida como "aplicación” o "ejecución” o, por el contrario, como "infracción" de preceptos jurídicos. ${ }^{17}$

Frente a la posición formalista, a fines del siglo XIX y principios del siglo XX, se da en el mundo anglosajón una importante reacción, representada por el denominado "realismo jurídico norteamericano", así como en Alemania la corriente conocida como "escuela del derecho libre" que — aunque con menos difusión y trascendencia- comparte su carácter radicalmente crítico al formalismo. ${ }^{18}$

El realismo jurídico ha presentado diversas versiones, todas ellas antiformalistas, de ahí que se parte de que las decisiones de los jueces son consecuencia de su subjetividad y de factores extrajurídicos, existiendo, en consecuencia, escepticismo, ya sea hacia las normas, los hechos o las personas que toman las decisiones judiciales.

Como bien lo apunta Feteris, ${ }^{19}$ en el siglo XX se modificaron las ideas acerca de las tareas del legislador y del juez, al determinarse que el legislador no puede prever todos los casos posibles.

Ello ha generado, de una u otra forma, cierto descrédito de la ley, adquiriendo relevancia la típica discusión entre positivismo e iusnaturalismo.

Autores como Hans Kelsen criticaron la doctrina tradicional, al considerar que el legislador aplica la Constitución y crea normas generales, mientras que el juez aplica la ley y crea sentencias, es decir, normas individuales. Por lo tanto, la diferencia entre la función del legislador y la del juez es solo cuantitativa: el juez suele estar más limitado que el legislador, pero ambos crean derecho dentro del marco establecido por la norma superior. ${ }^{20}$

El positivismo de Kelsen parte de que el sistema jurídico es completo, aspecto en que en cierta forma coincide con el formalismo jurídico, no obstante, admite la existencia de indeterminaciones lingüísticas.

17 Weber, Economía y sociedad, 741.

18 Diego Duquelsky, "El rol del juez en una sociedad democrática", Revista de Direitos e Garantias Fundamentais 16, 2 (2015), acceso el 21 de abril de 2018, http://sisbib.emnuvens.com.br/direitosegarantias/article/view/728/264

19 Feteris, Fundamentos de la argumentación jurídica, 27.

20 Bulygin, Los jueces ¡crean derecho?, 24. 
Por su parte, el modelo positivista de la discreción judicial de H. L. A. Hart sostiene que no se puede demostrar que una decisión judicial es la única correcta, pero es posible conseguir que se la acepte como el producto razonado de una elección imparcial bien informada, ello debido a que el derecho no tiene un carácter cerrado, existiendo casos fáciles (caen en la zona de claridad), en los que el juez no ejerce ninguna discrecionalidad, sino que se limita a descubrir un significado ya existente, y de casos difíciles (caen en la zona de la penumbra) en los que el juez necesariamente tiene que decidir, esto es, ejerce su discrecionalidad, aunque no lo haga arbitrariamente, definiéndose por la ausencia de respuesta correcta.

Tal y como lo anota Duquelsky, ${ }^{21}$ Hart y su obra El concepto de derecho, de 1963, representa para el mundo anglosajón lo que Kelsen y su Teoría pura del derecho de 1934 significa para la tradición de origen continental europea.

El formalismo jurídico puro, como se adelantó, desde hace muchas décadas (con posterioridad a la Segunda Guerra Mundial) se ha ido relegando a un segundo plano. La aplicación del derecho se ha encaminado hacia una tendencia que reconoce la prevalencia de los principios generales del derecho (de naturaleza mutable y elástica), a fin de suplir las carencias normativas, convirtiéndose el juez en un protagonista, consolidándose su función en lo que a la interpretación del derecho se refiere.

La teoría moderna de los principios se remonta a Ronald Dworkin, quien vino a revivir el tema de la única respuesta correcta en el campo del Derecho, fortaleciendo el dogma de la plenitud del Ordenamiento jurídico, pero no entendido sólo como normas positivas o reglas, sino otorgándosele importancia a los principios del derecho a partir de los cuales estima es posible lograr dicho cometido, rechazando, la discreción judicial.

El reconocimiento de la prevalencia de los principios generales sobre la ley positiva ha abierto un amplio espacio para las técnicas de la argumentación jurídica y, concretamente, para la ponderación como método interpretativo, cuyo mayor representante ha sido Robert Alexy, quien recogió algunas ideas fundamentales de Dworkin.

Conforme lo indica Alexy, ${ }^{22}$ existe acuerdo en la discusión metodológico-jurídica contemporánea en que la decisión jurídica, que pone fin a una disputa jurídica, expresable en un enunciado normativo singular, no se sigue lógicamente, en muchos casos, de las formulaciones de las normas jurídicas, que hay que presuponer como vigentes, juntamente con los enunciados empíricos que hay que reconocer como verdaderos o probados, existiendo al menos cuatro razones que lo explican: (1) la vaguedad del lenguaje jurídico, (2) la posibilidad de conflictos de normas, (3) el hecho de que sean posibles casos que necesitan una regulación

21 Duquelsky, El rol del juez en una sociedad democrática, 130.

22 Robert Alexy, Teoría de la argumentación jurídica (Madrid: Centro de Estudios Políticos y Constitucionales, 2012), 23-24. 
jurídica, pero para cuya regulación no existe una norma vigente, y (4) la posibilidad de decidir incluso contra el tenor literal de una norma en casos especiales.

En la actualidad, es un hecho incuestionable que los jueces tienen la obligación de resolver los casos que se les presente y tienen, al mismo tiempo, prohibido negarse a producir una sentencia argumentando inexistencia de normas para el caso puesto a su consideración. Por ello es que, en ciertas circunstancias, el juez es creador de derecho.

La función creadora de normas que tienen los jueces es ampliamente reconocida y se fundamenta, sobre todo, en la prohibición de denegar justicia. ${ }^{23}$

En similar sentido, Martínez ${ }^{24}$ refiere que los jueces crean derecho debido principalmente a dos fenómenos jurídicos: a) la existencia de lagunas y conflictos entre normas, b) la indeterminación y ambigüedad de los textos jurídicos, encontrándonos en ambos eventos ante la discrecionalidad del juez, la cual no implica un acto de arbitrariedad ni de extralimitación de funciones, sino que es simplemente el resultado inevitable y necesario de los dos fenómenos explicados anteriormente.

En síntesis, y aun cuando la actividad judicial debe moverse siempre al amparo de los principios y normas del sistema, ello no impide que su labor sea creadora. ${ }^{25}$

En este contexto, surge la necesidad de analizar si el juez en un Estado de derecho tiene legitimidad y, de ser así, en qué consiste esta; tópicos que de seguido serán estudiados.

\section{LA LEGITIMIDAD DEL JUEZ EN UN ESTADO DE DERECHO}

Kriel, ${ }^{26}$ citado por Báez, ${ }^{27}$ señala que Max Weber encuentra la legitimidad racional en la legalidad de los órdenes positivos y en el derecho de mandar de quienes están autorizados por ellos.

Para Weber, ${ }^{28}$ la dominación legítima de carácter racional descansa en la creencia en la legalidad de ordenaciones estatuidas y de los derechos de mando de las personas designadas por esas ordenaciones a ejercer la autoridad.

23 Bernd Rüthers, Teoría del derecho. Concepto, validez y aplicación del derecho (México: UBIJUS Editorial, 2009), 449.

24 Lina Martínez, "La actividad judicial: el texto frente a la realidad", Universitas, n. ${ }^{114}$, (2007), acceso el 7 de abril de 2018, http://revistas.javeriana.edu.co/index.php/vnijuri/article/viewFile/14599/11777

25 Manuel Segura Ortega, "La creación judicial del derecho", en Teoría y metodología del derecho. Estudios en homenaje al profesor Gregorio Peces-Barba. Vol. 2 (Madrid: Editorial Dykinson, 2008), 1065-1076.

26 Martin Kriele, Introducción a la teoría del Estado (Buenos Aires: Depalma, 1980), 27.

27 Carlos Báez, "Las decisiones judiciales: entre la motivación y la argumentación", en Estudios sobre interpretación y argumentación jurídicas, ed. por Carlos Báez, David Cienfuegos y Sergio Guerrero (México: Editora Laguna, 2010), 25.

28 Weber, Economía y sociedad, 172. 
El Estado, además de crear el derecho, lo respalda con su poder, siendo una de sus finalidades el garantizar el respeto a las normas jurídicas, imponer la "ley y el orden". Para ello establece órganos especializados en aplicar el derecho a los casos concretos (tribunales) y en imponerlo coactivamente a los ciudadanos cuando es preciso. ${ }^{29}$

En otras palabras, el juez, al dictar las sentencias ejerce un acto de autoridad. Lo que queda por dilucidar es cómo se ha conceptualizado su legitimidad en un Estado de derecho y si admitir la tesis de que "crea derecho", violenta dos principios democráticos básicos, a saber, la división de poderes y concretamente la legalidad.

Para algunos autores como Uprimny, ${ }^{30}$ el juez carece de legitimación democrática en un Estado de derecho, al no tener una fuente de poder autónomo, debiendo limitarse a respetar las decisiones tomadas mayoritariamente por los órganos políticos de origen popular.

En otro sentido, Ibánez ${ }^{31}$ sostiene que la legitimidad del juez no es formal sino materialmente democrática, en cuanto su función está preordenada y es esencial para la garantía de los derechos fundamentales, que constituyen la "dimensión sustancial de la democracia", y debe ajustarse estrictamente a la legalidad constitucionalmente entendida, siendo, así, esta su vía de conexión con la soberanía popular. Se trata de una clase de legitimidad que no es asimilable a la derivada de la litúrgica investidura de las magistraturas del Estado liberal: sacramental y para siempre; sino condicionada y estrechamente vinculada a la calidad de la prestación profesional, sometida a la crítica pública y a eventuales exigencias de responsabilidad previstas en el ordenamiento. Por ende, su legitimación no puede depender del sufragio, sino que, cumplidas las exigencias legales precisas para el acceso a la función, la legitimación se tiene (o no) por el correcto ejercicio de aquella dentro de los parámetros constitucionales y legales.

Aunque el juez carece de legitimación constitucional y de habilitación legal para emanar normas jurídicas de carácter general propiamente hablando, expone Ibánez, ${ }^{32}$ el modo del operador judicial no responde a lo denotado por el verbo "crear" en la primera acepción del Diccionario ("producir algo de la nada"); pero sí a una de las concreciones de la segunda: "establecer [...] por primera vez una cosa", si bien, partiendo, no ya de "la nada", sino de algunos datos o elementos preexistentes, para llegar a un resultado que, como tal, previamente no estaba dado y siempre podría haber sido otro.

29 Ángel Latorre, Introducción al derecho (Barcelona: Ariel, 2012), 25.

30 Rodrigo Uprimny, "La motivación de las sentencias", Pensamiento jurídico, n. ${ }^{\circ} 4$ (1996), acceso el 7 de abril de 2018 , http://www.revistas.unal.edu.co/index.php/peju/article/view/38998/pdf_330

31 Perfecto Ibáńez, "Democracia con Jueces", en La función judicial. Ética y democracia, ed. por Jorge Malem, Jesús Orozco y Rodolfo Vásquez (Barcelona: Editorial Gedisa S. A., 2003), 252.

32 Perfecto Ibánez, Tercero en discordia. Jurisdicción y juez del Estado constitucional (Madrid: Editorial Trotta, 2015), 302305. 
Los jueces al dar cumplimiento al principio de legalidad, al fundamentar y motivar sus actos, no solo encuadran su actuación al concepto de Estado de derecho, sino que se convierten en verdaderos regeneradores de la legitimidad del poder del Estado, en particular del poder político que ejercen mediante sus actos jurisdiccionales. $\mathrm{Al}$ argumentar sus decisiones, cumplen con una necesidad política; justificar el ejercicio del poder que se les ha conferido. Debido a su naturaleza de decisión estatal, la sentencia presupone la existencia de un monopolio de la violencia legítima; el juzgador tiene tras de sí todo el aparato coercitivo del Estado para obligar a que sus decisiones se acaten. Las decisiones pueden hacerse acatar por la fuerza, pero no por cualquiera, sino por la fuerza legítima. ${ }^{33}$

La legitimidad del juez en un Estado democrático y de derecho, necesariamente conduce al estudio de otro tema esencial: la importancia de la fundamentación o motivación de las sentencias.

\section{LA FUNDAMENTACIÓN DE LAS SENTENCIAS EN UN ESTADO DE DERECHO}

En palabras sencillas, "fundamentar" una sentencia significa dar argumentos o razones plausibles para justificar por qué se ha tomado precisamente esa decisión en lugar de otra. ${ }^{34}$

Sin duda alguna, la legitimidad del juez dependerá, en gran parte, de que la decisión que se dicte se encuentre debidamente fundamentada. Al respecto, Salas anota:

Hoy sabemos, y ciertamente desde los trabajos de Max Weber, que la diferencia formal entre un sistema jurídico autoritario-represivo y un sistema basado en la legalidad, reposa, esencialmente, en la circunstancia de que en el primero se recurre a expedientes autocráticos para legitimar los fallos judiciales: la voluntad del rey, los intereses de la clase dominante, los caprichos del dictador, mientras que en el segundo se acude a los medios técnicos que ofrece la burocracia judicial. Esta tesis constituye el núcleo de la "racionalidad de los medios y los fines" (Zweck-Mittel-Rationalität) y de la legitimidad del poder político. Con palabras aún más simples: la aceptación social y ética (o como diría Weber la "racionalidad formal") y, por ende, la legitimidad de una sentencia judicial dependen, en grandísima medida, de cómo esta sentencia sea fundamentada. De allí que la posibilidad de motivación sea un instrumento considerado esencial para la racionalidad de los fallos, pero también un importante mecanismo para ejercer la crítica sobre la actividad de los jueces. ${ }^{35}$

\footnotetext{
33 Báez, Las decisiones judiciales: entre la motivación y la argumentación, 27-28.

34 Minor Salas, "¿Qué significa fundamentar una sentencia? O del arte de redactar fallos judiciales sin engañarse a sí mismo y a la comunidad jurídica", Cuadernos electrónicos de filosofía del derecho, n. ${ }^{\circ} 13$ (2006), acceso el 7 de abril de 2018 , https://www.uv.es/cefd/13/minor.pdf

35 Salas, ¿Qué significa fundamentar una sentencia? ..., 2.
} 
La obligación de motivar las decisiones jurisdiccionales es una reconquista democrática de la modernidad. Si bien es cierto el pensamiento iluminista, que inspiró y alimentó la Revolución Francesa (1789), alzó como una de sus banderas la necesidad de prohibirle al juez interpretar las leyes, esto obedeció al momento histórico particular que se vivió hasta el siglo XVIII, a saber, la existencia de monarquías absolutistas que, a través de sus funcionarios, impartieron "justicia" de manera totalmente arbitraria y sin control alguno, lo que hizo que se propusiera la necesidad de que el juez fuera una especie de autómata, aplicador mecánico del silogismo clásico.No obstante, la imposibilidad práctica de mantener al juez atado a semejante dogma hizo que a lo largo de los siglos XIX y XX se impusiera un importante cambio en esta materia, pues se fue consolidando la práctica de motivar las decisiones, como una verdadera obligación del funcionario que resuelve en el marco de un régimen democrático. ${ }^{36}$

Conforme lo plantea Atienza, ${ }^{37}$ los cambios que se están produciendo en los sistemas jurídicos contemporáneos (sobre todo, la constitucionalización del derecho) parecen llevar a un crecimiento de la exigencia de la fundamentación, de argumentación, de las decisiones de los órganos públicos.

La fundamentación de una sentencia cumple esencialmente cuatro funciones básicas: (1) endoprocesal: plasmar por escrito las razones por las que se toma una decisión determinada, sirve como un mecanismo interno para que los tribunales superiores puedan ejercer un control (aunque sea mínimo) de los alegatos esgrimidos por los tribunales de instancias inferiores; (2) mostrar que las decisiones judiciales no son, ni pueden ser, estrictamente racionales; (3) legitimar el poder ejercido por el Estado sobre los ciudadanos (potestades de imperio de la administración pública), y (4) legitimar la administración de justicia frente a distintos foros de la sociedad, entre ellas, las partes involucradas. ${ }^{38}$

La superación del dogma de la completud del ordenamiento jurídico lleva a que hoy en día —utilizando la terminología de Atienza — hablemos de casos fáciles, difíciles y trágicos; siendo que en los primeros es posible acudir a cierto deductivismo (teoría formalista); sin embargo, en los dos últimos en muchas ocasiones tendrán que ponderarse principio o reglas del derecho.

En este sentido, Alexy refiere:

Existen dos operaciones fundamentales de aplicación jurídica: la subsunción y la ponderación. Mientras la subsunción ha sido relativamente bien investigada, en lo que concierne a

36 José Manuel Arroyo y Alexander Rodríguez, Lógica jurídica y motivación de la sentencia penal (San José: Editorial Jurídica Continental, 2002), 21.

37 Manuel Atienza, Curso de argumentación juridica (Madrid: Editorial Trotta, 2013), 21.

38 Salas, ¿Qué significa fundamentar una sentencia? ..., pp. 4-6. 
la ponderación, aún hay muchas preguntas por responder. Hay tres problemas básicos: el de la estructura, el de la racionalidad y el de la legitimidad. Entre estos problemas existen vínculos estrechos. La legitimidad de la ponderación en el derecho depende de su racionalidad. Cuanto más racional sea la ponderación, más legítima será la práctica de ponderaciones. Ahora bien, la estructura de la ponderación es decisiva para su racionalidad. Si los análisis revelaran que la ponderación no puede ser sino una decisión arbitraria, entonces sería cuestionable su racionalidad, así como su legitimidad en la jurisprudencia. ${ }^{39}$

Es evidente que en la praxis judicial no solo se presentan problemas a la hora de tomar decisiones ante la vaguedad del lenguaje jurídico, sino también ante la existencia de antinomias (conflictos de normas) y vacíos normativos (mal llamadas lagunas), surgiendo también como posibilidad el que se resuelva contra el tenor literal de una norma en casos especiales (sui géneris).

La exigencia de fundamentación de los pronunciamientos judiciales se traduce en un mayor control sobre los argumentos de la decisión judicial; sin embargo, en los llamados casos difíciles y trágicos podría suceder que el juez opte por "crear” derecho, quizás extralimitándose desde un punto de vista estrictamente formal (por las razones apuntadas líneas atrás), al considerar que la decisión más proporcionada o justa (perspectiva material) consiste en adecuar la norma a la realidad causando "el menor mal posible" para el caso concreto.

\section{CONCLUSIONES}

La doctrina tradicional planteó una división categórica entre la creación y la aplicación del derecho tomando como punto de partida uno de los principios estructurales más importantes que caracteriza al Estado de derecho: la separación de poderes.

Para Max Weber, la aplicación del derecho implica la subsunción de normas generales y preceptos singulares que el pensamiento jurídico deriva de ellas a "hechos concretos", lo que lo enmarca como un autor cercano a la corriente formalista, en la que la racionalidad y la sistematicidad juegan un papel preponderante, siendo irracional desde su óptica que las decisiones judiciales dependan de apreciaciones valorativas de índole ética, sentimental o política o que atiendan principios materiales como la moralidad, equidad y conveniencia. Con ello, este autor se aleja de lo que hoy conocemos como realismo jurídico.

Si bien, ya desde la época de Weber se decía que los juristas prácticos modernos exigían del juez una actividad "creadora", lo cierto es que en la actualidad el debate en cuanto a si los jueces crean o no derecho mantiene plena vigencia.

39 Robert Alexy, Teoría de la argumentación jurídica (Madrid: Centro de Estudios Políticos y Constitucionales, 2012), 2324. 
Actualmente, la interpretación no puede ser visualizada de manera extremista: ni deductivismo optimista ni escepticismo drástico. Dependiendo de la redacción de las normas, la interpretación será más o menos discrecional.

El intérprete, aparte de analizar reglas del derecho, en no pocas ocasiones debe ponderar principios, los cuales contribuyen a darle coherencia y consistencia al ordenamiento jurídico, permitiendo su homogeneidad.

Ante este panorama, surge el cuestionamiento (la discusión no está acabada) sobre si el juez tiene o no legitimidad democrática.

En nuestros días, es posible afirmar que la legitimidad del juez es materialmente democrática y se tiene (o no) por el correcto ejercicio de aquella dentro de los parámetros constitucionales y legales.

La exigencia de una adecuada y razonable motivación o fundamentación de la sentencia es una garantía político-institucional en la toma de decisiones en la medida en que permite controlar la actividad jurisdiccional (evitando se dé una extralimitación de sus funciones) y, consecuentemente, la legitimidad democrática de los jueces.

La realidad muestra que en el lenguaje jurídico hay términos vagos e indeterminados, que existen conflictos entre normas y vacíos legales, así como que en casos sui géneris la "mejor decisión" no necesariamente es la que se basa en el tenor literal de la norma (formalidad), sino que podría ser la que atiende a principios con un contenido material.

Por ello, se concluye que el tema investigado, hoy, más que nunca, está abierto para la reflexión.

\section{REFERENCIAS}

- Aguiló Regla, Josep. Teoría general de las fuentes del Derecho (y el orden jurídico). Barcelona: Editorial Ariel, 2012.

- Alexy, Robert. Teoría de la Argumentación Jurídica. Madrid: Centro de Estudios Políticos y Constitucionales, 2012.

- Arroyo Gutiérrez, José Manuel y Rodríguez Campos, Alexander. Lógica juridica y motivación de la sentencia penal. San José: Editorial Jurídica Continental, 2002.

- Atienza, Manuel. Curso de argumentación jurídica. Madrid: Editorial Trotta, 2013. 
- Báez Silva, Carlos. "Las decisiones judiciales: entre la motivación y la argumentación”. En Estudios sobre interpretación y argumentación jurídicas. ed. por Carlos Báez, David Cienfuegos y Sergio Guerrero, 11-34. México: Editora Laguna, 2010.

- Bulygin, Eugenio. “Los jueces ¿crean derecho?”. En La función judicial. Ética y democracia, ed. por Jorge Malem, Jesús Orozco y Rodolfo Vásquez, 21-38. Barcelona: Editorial Gedisa S. A., 2003.

- Duquelsky Gómez, Diego. "El rol del juez en una sociedad democrática”. Revista de Direitos e Garantias Fundamentais 16, vol. 2 (2015): 121-148. Acceso el 21 de abril de 2018. http://sisbib.emnuvens.com.br/direitosegarantias/article/view/728/264 https://doi.org/10.18759/rdgf.v16i2.728

- Ezquiaga Ganuzas, Francisco. "Función legislativa y función judicial: la sujeción del juez a la ley". En La función judicial. Ética y democracia, ed. por Jorge Malem, Jesús Orozco y Rodolfo Vásquez, 39-56. Barcelona: Editorial Gedisa S. A., 2003.

- Ferrajoli, Luigi. Derecho y razón. Teoría del garantismo penal. Madrid: Editorial Trotta, 2011.

- Feteris, Eveline. Fundamentos de la argumentación jurídica. Revisión de las teorias sobre la justificación de las decisiones judiciales. Bogotá: Universidad Externado de Colombia, 2007.

- Gascón Abellán, Marina y García Figueroa, Alfonso. La argumentación en el derecho. Algunas cuestiones fundamentales. Lima: Palestra Editores, 2003.

- Hillmann, Karl. Diccionario enciclopédico de sociología. Barcelona: Editorial Herder, 2001.

- Ibánez, Perfecto. Tercero en discordia. Jurisdicción y juez del Estado constitucional. Madrid: Editorial Trotta, 2015.

- Ibánez, Perfecto. "Democracia con Jueces". En La función judicial. Ética y democracia, ed. por Jorge Malem, Jesús Orozco y Rodolfo Vásquez, 245-264. Barcelona: Editorial Gedisa S. A., 2003.

- Kriele, Martin. Introducción a la teoría del Estado. Buenos Aires: Depalma, 1980.

- Latorre, Ángel. Introducción al derecho. Barcelona: Ariel, 2012.

- Martínez Escobar, Lina. "La actividad judicial: el texto frente a la realidad". Universitas 114 (2007): 291-318. Acceso el 7 de abril de 2018. http://revistas.javeriana.edu.co/index. $\mathrm{php/vnijuri/article/viewFile/14599/11777}$

- Salas, Minor. "¿Qué significa fundamentar una sentencia? O del arte de redactar fallos judiciales sin engañarse a sí mismo y a la comunidad jurídica”. Cuadernos electrónicos de 
filosofia del derecho, n. ${ }^{\circ} 13$ (2006): 1-18. Acceso el 7 de abril de 2018. https://www.uv.es/ cefd/13/minor.pdf

- Segura Ortega, Manuel. "La creación judicial del derecho". En Teoría y metodología del derecho. Estudios en homenaje al profesor Gregorio Peces-Barba. Vol. 2, 1065-1076. Madrid: Editorial Dykinson, 2008.

- Rüthers, Bernd. Teoria del derecho. Concepto, validez y aplicación del derecho. México: UBIJUS Editorial, 2009.

- Theodorson, George y Achilles Theodorson. Diccionario de sociología. Buenos Aires: Editorial Paidós, 1978.

- Uprimny Yepes, Rodrigo. "La motivación de las sentencias". Pensamiento jurídico, n. ${ }^{\circ} 4$ (1996): 131-139. Acceso el 7 de abril de 2018. http://www.revistas.unal.edu.co/index. php/peju/article/view/38998/pdf_330

- Weber, Max. Economía y sociedad. Edición revisada, comentada y anotada por Francisco Gil Villegas. México: Fondo de Cultura Económica, 2014.

RECIBIDO: $24 / 04 / 2018$

APROBADO: $20 / 10 / 2018$ 


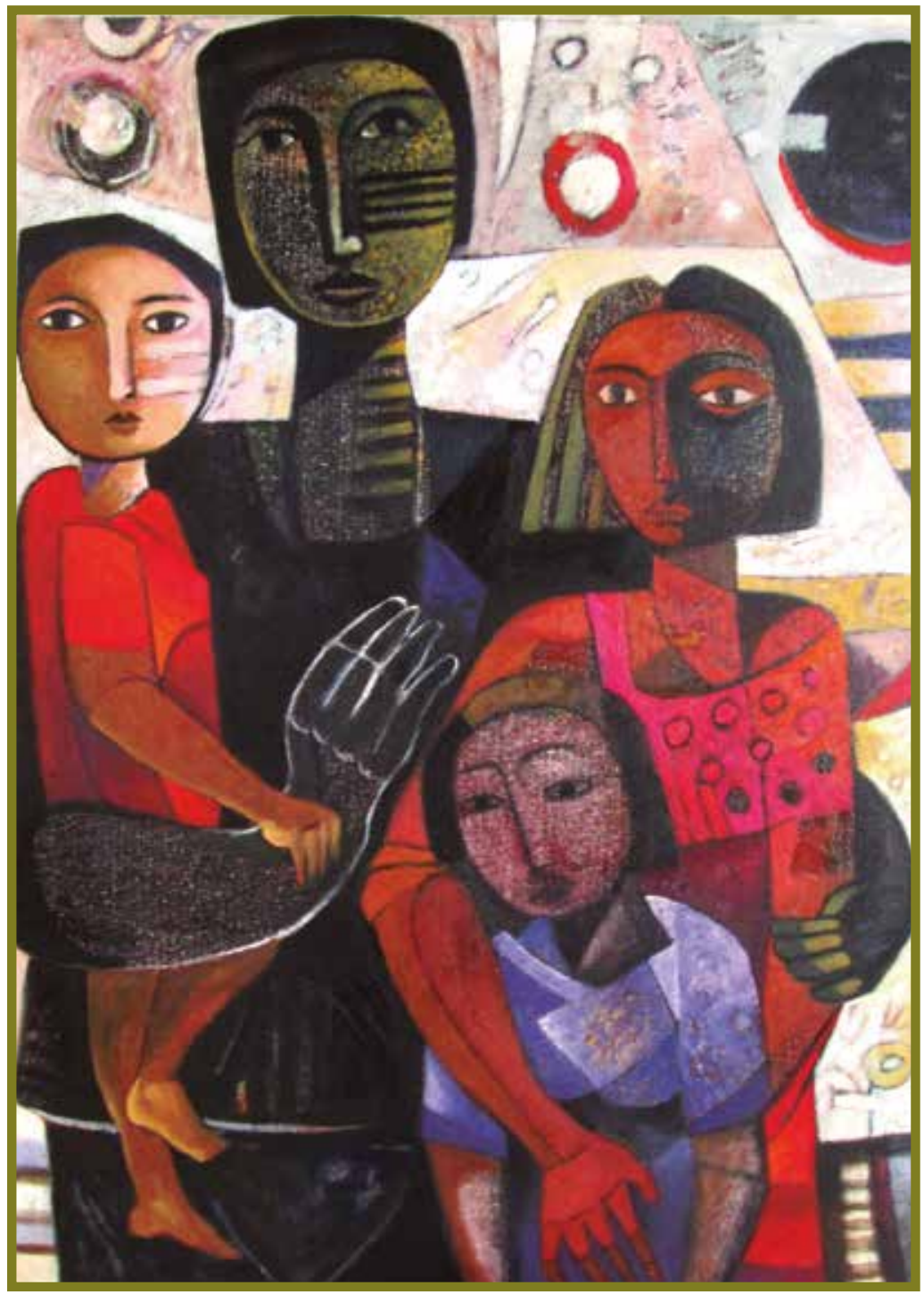

Familia 2. Pintura. Juan Carlos Nananake. 